\title{
The Effect of Using Smart Board on the Achievement of Tenth Grade Students in English language and on Verbal Interaction during Teaching in Public Schools
}

\author{
Nibal Abdelkarim Mousa Malkawi (Corresponding author) \\ Department of English Language and Literature \\ Al Balqa Applied University, Salt, Jordan \\ E-mail: nibal_malkawi@yahoo.com
}

Received: March 8, 2017 Accepted: March 23, 2017 Published: March 31, 2017

doi:10.5296/ire.v5i1.11035 URL: http://dx.doi.org/10.5296/ire.v5i1.11035

\begin{abstract}
This study aimed to investigate the effect of using the smart board on the achievement of tenth grade students in the English language, and verbal interaction, where the study sought to answer two questions:

Does the achievement of tenth grade students in English language vary due to teaching strategy?

Does the ratio of verbal interaction using smart board in teaching among tenth grade students vary from the ratio of verbal interaction at Flanders? (81) students from two sections chosen randomly from among (5) sections participated in the study, the experimental and control groups were chosen randomly, the experimental group were taught using smart board, and the control group were taught using the traditional way supported by computer. Achievement test in English language was applied, and Flanders' modified tool for the analysis of the verbal interaction was applied on the experimental group. The results showed the existence of significant differences in the achievement of the students; and in favor of the experimental group. The results showed a statistically significant difference in the ratio of speech of students who were taught using smart board. And the rate of teachers' speaking during teaching with smart board has increased, and periods of interruption verbal communication, and the percentage of questions rose by the teacher and her encouragement to her students, and the responses of the students and their initiatives.

In light of the findings, the study recommends the need to urge teachers to use the smart board in the teaching of the English language, and holding workshops to train teachers on
\end{abstract}


how to use the smart board in teaching, and conducting studies reveal the reality of the use of the smart board.

Keywords: smart board, achievement in English, verbal interaction

\section{Introduction}

The use of technological media in education like the computer, the Internet, and a data projector, the projector optic, smart board, are considered of the media that will help to bring about effective learning. some efforts have been made and studies have been conducted to investigate the effect of the use of certain media technology in the development of educational computer skills use in general, and among these studies Abed study (2007), which aimed to identify the effectiveness of a proposed program to develop the programming skill among teachers, and the study of the Aqel (2007), which aimed to investigate the effectiveness of the program (WebCT) in the development of the skill of designing visual computerized forms among the female students in the Faculty of Information and Technology. And Audeh (2005) held a study in order to identify a proposed program to train teachers on the production of educational techniques. while the study of Hasan (2005) was aimed to detect the effectiveness of the technical program for the development of practical skills in teaching technology among the Student/ teachers. And Hifnauy (2005) held a study in order to identify the effectiveness of multi-media in the development of the necessary programming skills among high school computer teacher.

With so many elements of the educational situation, including educational goals and the method of teaching, methods and activities the interests vary, but the biggest concern was the widespread change of the teaching methods and the use of technological innovations. It has contributed to the scientific progress and the rapid technological explosion, which in turn is reflected in the educational process, and in particular on the use of multimedia technology in education. Recent years have seen tremendous progress in technological media, and how to employ them and their use in education, and among these technological media the smart board (Gosaibi, 2009).

Smart board is an electronic board connected to a computer laptop or desktop device and Data Show and both the teacher and the learner can use this board as a white board by writing on it by using a special pen or fingers. Smart board allows the user multiple options by opening all computer applications and World Wide Web, and work on it through touch and clicking your fingers, as well as the use of different writing and drawing tools. And it allows viewing the text, images, audio and video files with various extensions. The user of smart board can move any element on the screen with the finger of the hand, such as moving graphics, shapes, and create virtual forms with original shapes. Through the use of smart board teacher can record and replay the presentation of lessons after saving it (Saraya, 2009; Swaidan, 2008).

With regard to educational software, the most important skills of producing it is employing multimedia, which depends on the employment and engaging of more than one sense (Zoubi, 2011) smart board is featured with its proximity to the interaction of tools based on the 
multiplicity of senses, in addition to containing many multimedia employing tools (Abu Elbah, 2012) as the use of smart board requires students to work directly with its tools and interact with it, and the involvement of more than one sense.

\subsection{Statement of the Problem}

Hardware and software programs are combined by smart board to create an interactive show that allows presenters to display and manipulate information on the screen for the audience to view. This technology operates by touch or by pens, and it is used for business presentations or lessons in the classroom. Smart board is a useful tool; however, there are challenges users commonly face while using smart board. The researcher tried to investigate the effectiveness of using it for teaching English Language at public schools at public schools in Jordan.

\subsection{Significance of the Study}

The importance of the study stems from the importance of smart board as a modern method of teaching which is consistent with global and local principles in the adoption of the principle of the use of technology in teaching (NCTM, 2000).

Teachers need to know all new in the field of education especially of what raises his efficiency in teaching, so this study may yield results that can be guided by them in the use of smart board as a means improved learning outcomes, it also derives its significance from improving students' learning of English language and its rules, and its contribution to open the way for other researchers to study the effect of using the smart board on other variables or in different age categories, teachers and educational decision-makers and curriculum developers can benefit from the results of this study.

\subsection{Purpose of the Study}

This study aimed to investigate the effect of using the smart board on the achievement of tenth grade students in the English language, as well as their verbal interaction.

\subsection{Questions of the Study}

The study tried to answer the following questions

1. Does the achievement of tenth grade students in English language differ according to the teaching strategy (the use of Smart Board, the current way aided by computer)?

2. Does the level of verbal interaction among tenth grade students when using smart board in teaching differ from verbal interaction at Flanders?

\subsection{Definition of Terms}

Smart board: Hardware and software programs are combined by the smart board to create an interactive whiteboard that allows presenters to display and manipulate information on the board for the audience to view. The board operates by touch or by pens that are provided with the board. The smart board was used in teaching English language from the tenth grade English textbook. 
English achievement: The total marks obtained by the student in English achievement test directly after finishing the experiment.

\subsection{The Study Limitations}

The English achievement and retention of the students were measured through an achievement test prepared by the researcher, so the results are connected to the test questions from its validity and suitability to the subject.

\section{Review of Related Literature}

Abu Elbah (2012) study aimed to investigate the impact of a program that employs smart board in the development of practical skills in electrical diagrams among ninth grade students in Gaza, and the results showed that the program, which employs smart board is characterized by high-actively in the development of practical skills in electrical schemes for students of ninth grade .

Swan et al. (2008) conducted a study that aimed to verify if the use of smart board lead to improved academic achievement for students in the English Language and Mathematics. Performance tests in reading and math which are used at the level of the state of Ohio, USA were used to compare students' achievement from the third grade to eighth grade in basic education in one of the state schools. Dozens of students whose teachers use smart board and students whose teachers did not use smart board shared in this study. Results showed slightly higher performance for students who have used the smart board and especially in the fourth and fifth grades students, the study recommended further studies to ascertain the impact of smart board in a clearer and stronger way.

Smith et al. (2006) conducted a study in which they sought to determine the impact of smart board to increase the interaction between teacher and student in reading, writing and arithmetic quotas, but to achieve this (184) classes has been viewed over two years to a sample of teachers of primary school has been teaching using smart board and without it, and by using a computerized show form. The study found that Smart board led to some changes in the interaction between teacher and student.

Hasballah (2002) conducted a study aimed to prepare a list of the trend toward the use of electronic board and to determine whether the students/ teachers in Mathematics section accept or refuse the use of electronic board in teaching, and determine the dimensions (axes) list, which included the basic dimensions of the emotional domain, which are knowledge and propensity and conscience. The results showed that there is statistically significant difference between mean scores of students of research group in the two applications pre and post on the list of students' attitudes towards the use of electronic board in favor of the post application.

Marzano and Haystead (2009) conducted a study aimed to determine the effect of smart board on the academic achievement of students where it included 85 teachers and 170 classrooms the teachers used smart board to teach a series of lessons, which have been taught later to a different group of students without the use of technology where the results indicated that the use of smart board was accompanied by an increase of $16 \%$ in student achievement 
scores, there was statistically significant differences in favor of the use of smart board.

Torff and Tirotta (2010) conducted study to determine the extent to which use of interactive whiteboard technology (IWB) was associated with upper elementary students' self-reported level of motivation in mathematics. The study's participants included 773 students (241 students in 4th grade, 260 in 5th grade, and 232 in 6th grade). There were 32 participating teachers: 19 who indicated they were IWB users (the treatment group) and 13 who indicated that they were not extensive users of the IWB (the control group). The treatment group included 458 students and the control group had 315 students. The results of the study revealed that the students in the treatment group reported higher levels of motivation relative to control students. Students with teachers who were more supportive of IWB technology reported higher motivation levels (compared to students of teachers who were less supportive).

Wall et al. (2005) conducted survey research in which 80 students filled out templates with questions that asked them what they thought of the IWB and what they were likely to share with others about this technology. A total of 1568 responses were analyzed; 883 of the statements were judged to be positive, 494 statements were scored as neutral, and 191 were judged to be negative. Positive statements were then broken down into subcategories, with "motivation" and "fun" each noted in over 120 responses. The researchers concluded that students deemed the IWB to be motivational and fun, especially when students were able to see their work projected on the IWB screen.

\section{Methodology of the Study}

This study has adopted the quasi-experimental method, to check the impact of Using the smart board on the achievement of the tenth grade students in English language and in verbal interaction, and the study included two groups: the first experimental and the second control, the experimental group studied using the smart board, and the control group studied using normal board which is computer-supported, an achievement pre/test was conducted on the two groups, and then it is re-applied on them after the completion of the experiment.

\subsection{Sample of the Study}

The study included 81 tenth grade students from one of the schools at Wadi el-Seer Directorate of education in Amman Governorate for the academic year 2016/2017 distributed into two sections, both sections were chosen randomly out of (5) sections, and both sections were divided randomly assigned to two groups of the study, the experimental group (40) Students, and the control group (41) students.

\subsection{Variables of the Study}

\section{(1) Independent variable:}

The use of smart board in teaching, it has two levels:
A. teaching strategy using smart board
B. normal teaching strategy using a normal computer-supported board 
(2) Dependent variables:

A. The achievement of tenth grade students in the English language

B. Verbal interaction for the students of tenth grade in the course of the teaching process.

\subsection{Study Tools}

To achieve the goal of the study to detect the effect of using the smart board on the achievement of tenth grade students in English language and verbal interaction, the following tools were used:

\subsubsection{First: Achievement Test}

The researcher developed an achievement test in English language to measure the skills, the information and expertise that the students acquire through learning by using the smart board.

\subsubsection{Second, Analysis of Verbal Interaction by Observation}

In the current study the tool of Flanders was used which was amended by Farra (2004), this tool consists of four categories each one includes Rating four behavioral categories, and the number of these categories is sixteen behavioral categories, the tool is appended with a category included comments and other additives used by the observer.

\subsection{Statistical Treatment}

Means and standard deviations for the performance of students on the achievement test were calculated, and by analysis of variance for the study two groups, and the (ANCOVA) results and (t-test) of the sample were calculated to be compared to the ratio of verbal interaction for students in the experimental group with verbal interaction ratio at Flanders.

\section{Results of the Study}

\subsection{Results for the First Question and Its Discussion}

To answer the first question, which stated: What is the effect of using Smart board on the achievement of tenth grade students in English language? Means, amended standard deviations (ANCOVA) were calculated as the accompanying analysis of variance for the study two groups (experimental and control) where its findings shown in Table (1) and Table (2).

Table 1. Pre/post and amended means, standard deviations and errors for the performance of students on the achievement test for the two experimental and control groups

\begin{tabular}{lllllll}
\hline & Pre/test & & Post/test & \multicolumn{3}{c}{ Modified } \\
\hline Group & Mean & $\begin{array}{l}\text { Standard } \\
\text { deviation }\end{array}$ & Mean & $\begin{array}{l}\text { Standard } \\
\text { deviation }\end{array}$ & Mean & $\begin{array}{l}\text { Standard } \\
\text { deviation }\end{array}$ \\
Experimental & 7.76 & 2.29 & 9.76 & 2.99 & 8.949 & 0.366 \\
Control & 6.95 & 1.92 & 10.05 & 2.81 & 488.109 & 0.371 \\
Total & 7.36 & 2.14 & 9.90 & 2.89 & 9.91 & 0.29 \\
\hline
\end{tabular}


Table 2. The results of analysis of covariance (ANCOVA) for the performance of students on the achievement test in English language

\begin{tabular}{lllllll}
\hline $\begin{array}{l}\text { Source } \\
\text { variance }\end{array}$ & of & $\begin{array}{l}\text { Sum } \\
\text { squares }\end{array}$ & of & Df & $\begin{array}{l}\text { Mean } \\
\text { squares }\end{array}$ & of \\
\hline Pre/test & 452.213 & 1 & 452.213 & 192.41 & 0.000 \\
Group & 737.43 & 1 & 737.43 & 440.8 & $* 0.005$ \\
Error & 821.393 & 76 & 182.5 & & \\
Total & 304.616 & 78 & & & \\
\hline
\end{tabular}

It is clear in Table (1) the existence of morphological differences between amended Arithmetic means for the two groups experimental and control, to find out significance of differences by analysis of covariance, its results indicated in the Table (2).

Table (2) shows that there are statistically significant differences at the level $(\alpha=0.05)$ between the arithmetic mean of the performance of students of the experimental group and the arithmetic mean of the performance of students of the control group in the achievement test in English language, where the value of $F$ was (8.44) corresponds to the level of significance (0.005). These differences came in favor of the experimental group which used Smart board as shown in the Table (1).

It is evident from Table 1 that the amended arithmetic mean of the achievement post/test in English for the control group (8.949) and the standard error (0.366) while the amended arithmetic mean of the experimental group was $(10,488)$, and standard error $(0.371)$, which indicates that the performance of students at the experimental group is better than the performance of students at control group. This means that teaching method using a smart board has a positive impact on achievement in English Language When compared to the usual way.

This may be attributed to the use of the Smart board increases the attention of students as a result of the use of more than one sense in the Educational learning situation, forcing the student to focus and scrutiny and follow-up events, and increases the activity, and attracts attention to the existence of clear expressive colors, and helps the use of sound and the movement to attract attention and focus away from the dispersants.

Smart board may help to improve the students' experiences and stimulate their interest and satisfy their needs for learning, given that the Smart board displays the material in a variety of ways and exciting and attractive, which bring fun and diversity in learning situations for students.

\subsection{Results for the Second Question and Its Discussion}

To answer the second question: what is the effect of using Smart board in verbal interaction among tenth grade students during the teaching process? "T" test results were calculated to compare the ratios of One Sample T-Test (T) Verbal interaction for the students of the tenth grade and basic rates of verbal interaction at Flanders, Table (3) show those results. 
Table 3. Test results ( $t$ ) of the sample and the difference between the average rates of the sample and Flanders ratios for the behavioral Categories of verbal interaction for the experimental group

\begin{tabular}{|c|c|c|c|c|}
\hline Behavioral categories $* *$ & Mean & $\begin{array}{l}\text { percentage } \\
\text { Flanders }\end{array}$ & $\begin{array}{l}\text { Difference } \\
\text { between them }\end{array}$ & Sig \\
\hline Ratio of teachers' words & $\% 70.67$ & $\% 66$ & $67.4 \%$ & $024 * 0$ \\
\hline The ratio of students' talk & $00,21 \%$ & $\% 32$ & $-00,11 \%$ & $0,000 *$ \\
\hline The ratio of uninterrupted communication & $22,8 \%$ & $\% 3$ & $22,5 \%$ & $0,003 *$ \\
\hline the ratio of teachers' direct speech & $44,80 \%$ & $\% 84$ & $-56,3 \%$ & 0,067 \\
\hline the ratio of student's talk to teacher's talk & $11,30 \%$ & $\% 48$ & $-89,17 \%$ & $0,000 *$ \\
\hline Ratio of teachers' response to students & $22,18 \%$ & $\% 15$ & $22,3 \%$ & 0,081 \\
\hline $\begin{array}{l}\text { Ratio of teachers' questions from direct } \\
\text { speech }\end{array}$ & $44,34 \%$ & $\% 23$ & $44,11 \%$ & $0,000 *$ \\
\hline The ratio of praise and reinforcement & $00,17 \%$ & $\% 3$ & $00,14 \%$ & $0,000^{*}$ \\
\hline The ratio of students Initiative & $22,99 \%$ & $\% 93$ & $22,6 \%$ & $0,000 *$ \\
\hline The ratio of useful calmness & $56,60 \%$ & $\% 53$ & $56,7 \%$ & 0,294 \\
\hline The ratio of chaos and riots & $56,39 \%$ & $\% 47$ & $-44,7 \%$ & 0,305 \\
\hline
\end{tabular}

*Statistical significant at $\alpha=0.05$

**Some behavioral categories in Table (3) included more than behavioral category of the instrument categories compared with Flanders categories.

If we examine Table (3) is clear that there is a statistically significant difference in the ratio of teacher's talk, where the average reached $(70.67 \%)$ and matched the Level of significance (0.024), which is statistically significant. As the average ratio of teacher's speech than the ratio defined by Flanders (66\%) which indicates that the use of the smart board has increased the ratio of teacher's talk through teaching at the expense of ratio of the students' talk. This may be attributed to the teacher's focus on providing ideas and commands when using it, and guide students toward how to use the Smart board to explain the rule using it, and ask the students simple and quick questions, and perhaps criticizing them when the misuse or interaction is inappropriate. The teacher may be somewhat cautious as a result of the new usage of Smart board which forced them to continued guidance.

It is clear from the table also, that the ratio of students' talk is $(21 \%)$ corresponds to the level of significance (0000), which indicates the presence of a statistically significant difference in the ratio of the students' talk. As the ratio of the learners' talk, according to Flanders $(32 \%)$, this showed that the use the smart board has reduced the ratio of female students' talk.

The table also shows that the ratio of uninterrupted communication was (8) equivalent to the level of significance (0.003), which is statistically significant. And notes that the ratio of uninterrupted communication more than the ratio of Flanders $(3 \%)$. Which indicates that the use of smart board in teaching has increased the uninterrupted verbal communication between students and teacher, and without that there will be a verbal reaction from the students. This may be attributed to the students are busy in writing on the Smart board or on the book 
without talking.

With reference to Table 3 it shows that the ratio of teachers' direct speech is $(80.4 \%)$ corresponds to the level of significance $(0.067)$ a value which is not statistically significant. Comparing this ratio with Flanders ratio (84\%), we find that the use of Smart board in teaching reduced apparently the ratio of teachers' direct talk, so as to increase the ratio of teacher's indirect talk, suggesting an increase in response of teacher to her students (praise, promote and accept the feelings and thoughts of students). When using Smart board, this may be attributed to the pleasure of the teacher from the safety of the students and interacted with the Smart board and its tools.

As it can be seen from the same table that the ratio of students' talk to teacher's talk is $(30.1 \%)$, while the ratio of Flanders was $(48 \%)$. It is clear that the ratio of female students talk to teacher's talk corresponding to the level of significance $(0.000)$ which is statistically significant. Which indicates that the use of the Smart board has reduced the ratio of students to talk compared with teacher's talk, which means that the use of Smart board did not increase the students' verbal interaction. And by examining Table (3), we find that the ratio of teacher's response to students was $(18.2 \%)$ corresponds to the level of significance $(0.081)$ which is not statistically significant, while the ratio at Flanders was (15\%) and this indicates that the use of smart board in teaching ostensibly increased the teacher's response to students, where the ratio of teacher's praise and promote to her students increased, and her acceptance of their ideas and feelings during her talk and interact with them. Perhaps this result is attributable to the use of the Smart board to attract the attention of students to the lesson and stimulate them to ask questions and inquiries.

The results also showed that the ratio of teacher's questions of direct talk reached $(34.4 \%)$ corresponds to the level of significance $(0.000)$, Which is statistically significant, while the ratio of Flanders was (23) \% Which indicates that the use of Smart board increased the questions raised by the teacher in the course of explaining the lesson and managing and guiding the discussion in the classroom. It is clear from the table also that the ratio of praise and reinforcement and feedback and accept the feelings of the students and their ideas reached $(17 \%)$ corresponds to the level of significance $(0.000)$, which is statistically significant, while the ratio according to Flanders was (3\%). This means that the use of Smart board has increased the encouragement of the teacher to her students and providing immediate feedback to them.

The table also shows that the ratio of students Initiative reached $(99.2 \%)$ compared to the ratio of Flanders (93\%) corresponds to the level of significance $(0.000)$, which is statistically significant, suggesting that the use of Smart board has increased the students' response and their initiatives. Perhaps this is due to the large number of questions posed by the teacher that resulting in the student response, even if the ratio of the initiative from the student is little, this may be attributed to that the use of Smart board covers the different learning styles of students which boost Initiative among them.

It is clear from the table that the ratio of calmness reached (60.55\%), compared to Flanders $(53 \%)$ corresponds to the level of significance $(0.294)$, which is not statistically significant, 
suggesting that using smart board increase apparently the ratio of students' calmness in class and reduced the rate of riots in the lesson. This is may be due to the teacher's awareness of the clarification and provide guidance on how to use the Smart board which makes the students calm, and the high rate of calmness among students may be because students answer the questions using writing.

As it can be seen from the table that the chaos and riots reached (39.56\%) and the ratio was at Flanders $(47 \%)$ corresponds to the level of significance $(0.305)$ which is not statistically significant, meaning that the use of Smart board in teaching apparently reduced the proportion of Chaos and riots in the class.

\section{Conclusion}

It is evident from the results of this study and from previous literature that using technology in general helps the students to achieve better results. Smart board is an effective tool in teaching all subjects not only English language, it includes many facilities and it is suitable for all levels of students; it includes modified programs to deal with each student separately. Recently, in Jordan the use of smart board spread greatly in schools and it proved its success in the teaching and evaluation process.

\section{Recommendations}

In light of the results of this study the researcher recommends the following:

1. Urging the teachers to use the smart board in English Language Teaching.

2. The need to hold workshops to train teachers on how to use the smart board in teaching.

3. Conducting studies to investigate the effect of using the smart board in student achievement in other subjects and their attitudes toward it.

4. Conducting studies to investigate the impact of the use of smart board in students' achievement in other classes and its relationship with some variables.

5. The need to encourage teachers and urged them to reduce the explanation and continue to speak when you use the smart board in teaching.

6. Conducting studies on the reality of the use of smart boards in private schools.

\section{References}

Abed, A. (2007). Effectiveness of the proposed program to develop the programming skill of the teachers of technology at Gaza. Unpublished Master Thesis, the Islamic University, Gaza, Palestine.

Abu Elbah, A. (2012). The impact of the program employs smart blackboard in the development of scientific skills in electrical diagrams the basic ninth-grade students in Gaza. Unpublished MA Thesis, College of Education, the Islamic University of Gaza.

Aqel, M. (2007). The effectiveness of (WebCt) program in the development of visual forms of computerized skills among students of the Faculty of Information Technology at the Islamic 
University. Unpublished Master Thesis, the Islamic University, Gaza, Palestine.

Audeh, R. (2005). A proposed program to train teachers in the basic technology for the upper stage in Gaza province, the efficiencies of the design and production of educational techniques. Unpublished MA Thesis, Al-Azhar University, Gaza, Palestine.

Gosaibi, S. (2009). Effective use of interactive whiteboard in addressing some learning difficulties for students with special needs, Retrieved in 2016 from www.social-team.com

Hasballah, M. (2002). The effectiveness of the proposed program in the development of teachers/ students' attitudes towards the use of electronic blackboard. The Faculty of Education in Damietta, Mansoura University.

Hasan, M. (2005). A technical program for the development of process technology displays' skills in teaching technology to the Students/teachers. Unpublished MA Thesis, Islamic University, Gaza, Palestine.

Hifnauy, A. (2005). The effectiveness of multimedia in the development of the necessary programming skills among high school computer teacher training program. Unpublished Master Thesis, Institute of Educational Studies, University of Cairo.

Marzano, R. J., \& Haystead, M. (2009). Final report on the evaluation of the Promethean technology. Englewood Co: Marzano Research Laboratory.

Saraya, A. (2009). Educational Technology and sources of e-learning theoretical concepts and practical applications. Part II, Al Rushd library, Riyadh.

Smith et al. (2006). The impact of interactive whiteboards on teacher-pupil interaction in the national literacy and numeracy strategies. British Educational Research Journal, 32(3), 443-457. https://doi.org/10.1080/01411920600635452

Swaidan, A. (2008). The effectiveness of the use of smart blackboard in the development of educational programs production skills for kindergarten teachers in the light of their training needs. Conference of education and the education of Arab children Technology of the Arab Republic of Egypt (pp. 36-72).

Swan, K., Schenker, J., \& Kratcoski, A. (2008). The effects of the use of interactive whiteboards on student achievement. In J. Luca \& E. Weippl (Eds.), Proceedings of World Conference on Educational Multimedia Hypermedia and Telecommunications (pp. 3290-3297), Chesapeake, VA: AACE.

Torff, B., \& Tirott, R. (2010). Interactive whiteboards produce small gains in elementary students' self-reported motivation in mathematics. Computers \& Education, 54, 379-383. https://doi.org/10.1016/j.compedu.2009.08.019

Wall, K., Higgins, S., \& Smith, H. (2005). The visual helps me understand the complicated things': Pupil views of teaching and learning with interactive whiteboards. British Journal of Educational Technology, 36, 851-867. https://doi.org/10.1111/j.1467-8535.2005.00508.x

Zoubi, Sh. (2011). The impact of an educational program using the interactive whiteboard in 


\section{Macrothink}

International Research in Education

ISSN 2327-5499

2017, Vol. 5, No. 1

the academic achievement of science at the fifth grade students in Kuwait. Unpublished MA Thesis, University of Kuwait, Kuwait.

\section{Copyright Disclaimer}

Copyright reserved by the authors.

This article is an open-access article distributed under the terms and conditions of the Creative Commons Attribution license (http://creativecommons.org/licenses/by/3.0/). 